\title{
Waveguide Design Optimization for Long Wavelength Semiconductor Lasers with Low Threshold Current and Small Beam Divergence
}

\author{
Abdulrahman Al-Muhanna, Abdullah Alharbi, Abdelmajid Salhi \\ King Abdulaziz City for Science and Technology, KACST, \\ National Nanotechnology Research Center, Riyadh, Saudi Arabia \\ E-mail:asalhi@kacst.edu.sa \\ Received November 5, 2010; revised January 7, 2011; accepted February 8, 2011
}

\begin{abstract}
Long wavelength GaSb-based quantum well lasers have been optimized for high coupling efficiency into an optical system. Two approaches were used to reduce the vertical far-field. In the first approach we showed the use of $\mathrm{V}$-shaped Weaker Waveguide in the n-cladding layer dramatically reduces vertical beam divergence without any performance degradation compared to a conventional broad-waveguide laser structure. Starting from a broad waveguide laser structure design which gives low threshold current and a large vertical far-field (VFF), the structure was modified to decrease the VFF while maintaining a low threshold-current density. In a first step the combination of a narrow optical waveguide and reduced refractive index step between the waveguide and the cladding layers reduce the VFF from $67^{\circ}$ to $42^{\circ}$. The threshold current density was kept low to a value of $\sim 190 \mathrm{~A} / \mathrm{cm}^{2}$ for $1000 \times 100 \mu \mathrm{m}^{2}$ devices by careful adjustment of the doping profile in the p-type cladding layer. The insertion of a V-Shaped Weaker Waveguide in the n-cladding layer is shown to allow for further reduction of the VFF to a value as low as $35^{\circ}$ for better light-coupling efficiency into an optical system without any degradation of the device performance. In the second approach, we showed that the use of a depressed cladding structure design also allows for the reduction of the VFF while maintaining low the threshold current density $\left(210 \mathrm{~A} / \mathrm{cm}^{2}\right)$, slightly higher value compare to the first design.
\end{abstract}

Keywords: Semiconductor Laser, Far-Field, Simulation

\section{Introduction}

Antimonide materials have become increasingly important for a number of electronic and optoelectronic devices. In particular antimonide-based semiconductor laser diodes emitting in the $2-5 \mu \mathrm{m}$ range have attracted considerable attention for a variety of applications: trace gas sensing, military countermeasures, pollution monitoring and molecular spectroscopy $[1,2]$. In the $2-5 \mu \mathrm{m}$ wavelengths range, the best results, with low threshold currents and high optical powers, were achieved by type I GaInAsSb-AlGaAsSb diode lasers grown on GaSb substrates [3-9]. Continuous wave (cw) output powers as high as $1 \mathrm{~W}$ were demonstrated at room temperature at $\lambda \sim 2$ and $2.5 \mu \mathrm{m}[6,7]$. Beyond $2.75 \mu \mathrm{m}$ quantum cascade lasers based on InAs/AlSb also show promising results $[8,9]$. $\mathrm{Cw}$ operation of diode lasers, using type I GaInAsSb quantum wells with AlGaInAsSb barriers and emitting at $3.36 \mu \mathrm{m}$, has recently been achieved [10]. The results for type I lasers emitting between 2 and $3 \mu \mathrm{m}$, mentioned above, are based on a broadened-waveguide structure. The laser structure consists of a wide waveguide with two separate confinement layers (SCL), typically $375 \mathrm{~nm}$ in width enclosing the GaInAsSb quantum wells, and utilize $90 \%$ aluminum content cladding layers $[3,6,7]$. The wide-waveguide design produces a small overlap of the optical mode with the cladding layers resulting in low internal losses, $\alpha_{\mathrm{i}}$, and high modal gain as a result of the high quantum well confinement $\left(\Gamma_{\mathrm{QWs}}\right)$ $[3,11,12]$. The light coupling efficiency into an optical system of finite aperture is strongly dependent on the beam divergence in the fast axis which in the described design has a typical value of full width at half maximum (FWHM) of $70^{\circ}$. This large value makes it difficult to collect the laser power with standard optics. Therefore, to reduce VFF, new epitaxial structures were adopted. 
The new structures allow for a broader optical mode inside the waveguide without altering the confinement factor of the quantum wells and free carrier absorption in order to maintain the same characteristics. Normally, device characteristics are expected to degrade with a large optical field due to the increase of free-carrier absorption, particularly in the p-doped cladding. We take the additional precaution of tailoring the doping profile in the p-cladding layer in order to maintain low internal losses.

In this paper we propose new epitaxial structures for long wavelength $\mathrm{GaSb}$-based lasers which provide a small vertical beam divergence and low threshold-current density. The first new design includes a narrow optical waveguide and smaller refractive index step between the cladding and the waveguide layers. The insertion of a V-Shaped Weaker Waveguide (VSWW) in the n-cladding layer leads to considerable improvement of the vertical far-field FWHM. A value as low as $35^{\circ}$ is achieved in the new design nearly a $50 \%$ reduction of the far-field obtained with the conventional design $\left(67^{\circ}\right)$. The threshold current density was kept low to a value of $190 \mathrm{~A} / \mathrm{cm}^{2}$ for $1000 \times 100 \mu \mathrm{m}^{2}$ devices by a careful adjustment of doping in the highly absorbing p-doped cladding layer. In the second design, instead of inserting a VSWW in the n-cladding layer, two layers with low refractive index with respect to the cladding layers are inserted between $n$ and p-type cladding and the optical waveguide layers. This approach leads also to a reduction of the VFF to $34^{\circ}$ keeping the threshold current density to a reasonable value of $210 \mathrm{~A} / \mathrm{cm}^{2}$.

\section{Structure Design and Simulation}

The base-line structure used in the modeling consists of three 10-nm-thick $\mathrm{Ga}_{0.65} \mathrm{In}_{0.35} \mathrm{As}_{0.11} \mathrm{Sb}_{0.89}$ QWs, emitting at $\lambda=2.38 \mu \mathrm{m}$, separated by 35 -nm-thick $\mathrm{Al}_{0.25} \mathrm{Ga}_{0.75}$ $\mathrm{As}_{0.02} \mathrm{Sb}_{0.98}$ barriers and enclosed between 375-nm-thick $\mathrm{Al}_{0.25} \mathrm{Ga}_{0.75} \mathrm{As}_{0.02} \mathrm{Sb}_{0.98}$ confining layers. The waveguide is surrounded by two $\mathrm{Al}_{0.9} \mathrm{Ga}_{0.1} \mathrm{As}_{0.07} \mathrm{Sb}_{0.93} \mathrm{n}$-type $(2 \times$ $\left.10^{18} \mathrm{~cm}^{-3}, \mathrm{Te}\right)$ and p-type $\left(5 \times 10^{18} \mathrm{~cm}^{-3}, \mathrm{Be}\right)$ cladding

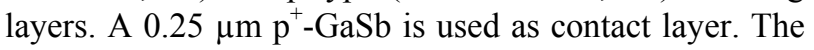
p-doping level of the first $0.2 \mu \mathrm{m}$ near the active zone was decreased to $5 \times 10^{17} \mathrm{~cm}^{-3}$ in order to reduce the free carrier absorption. Further details describing the laser structure can be found in [3]. The modeling of the near field, far-field and confinement factors of the optical modes was performed using FIMMWAVE from Photon Design. The threshold current density of the laser is performed by a HAROLD [13]. The laser software solves self-consistently the Poisson equation, the current continuity equations, the carrier's capture-escape balance equations, and the photon rate equation. In addition, it solves the vertical and longitudinal wave and Schrödinger's equations. It calculates also the optical gain using a parabolic band approximation. The carrier transport through the multi-quantum well structure is included in the model. The model allows also the calculation of the distribution of electron and hole concentrations, for both confined and unconfined carriers.

The calibration of the laser model was described in our previous work using the conventional laser structure described previously [12].

The model calibration leads to an Auger coefficient of $3.2 \times 10^{-28} \mathrm{~cm}^{6} \mathrm{~s}^{-1}$, a hole cross section in the quantum well of $\sigma_{\mathrm{p}-\mathrm{QW}}=80 \times 10^{-18} \mathrm{~cm}^{2}$. The hole cross section in the p-type cladding layers was fixed to $\sigma_{\mathrm{p} \text {-Clad }}=46 \times$ $10^{-18} \mathrm{~cm}^{2}$ as found experimentally in [11]. Figure 1 shows the refractive index profile of the conventional laser structure as structure $S_{1}$. In this structure the combination of a high refractive index step between the cladding and the waveguide layers of $\Delta \mathrm{n}=0.29$ (correspond to an aluminum content of $90 \%$ in the cladding layers and $25 \%$ in the waveguide) and a broad-waveguide leads to a small overlap of the optical mode with the cladding layers and a high value for the overlap of the optical mode with the quantum wells. The variation of $\Gamma_{\mathrm{QWs}}$ and VFF as a function of the waveguide thickness is presented in Figure 2. The VFF has a value as high as $67^{\circ}$ and $\Gamma_{\mathrm{QWs}}=4.4 \%$ for conventional laser structure $\mathrm{S}_{1}$ with a total waveguide thickness of $850 \mathrm{~nm}$. When the refractive index step is decreased in structure $\mathrm{S}_{1}$ to $\Delta \mathrm{n}=0.166$ (obtained by reducing the aluminum content to $50 \%$ in the cladding layers) the VFF and $\Gamma_{\mathrm{QWs}}$ decreases to $53^{\circ}$ and 3.75\%, respectively (Figure 2). Decreasing the waveguide thickness is accompanied by an increase of the threshold current density as a result of the increase of the free carrier losses. This behavior is illustrated in Figure 3 in which we show the threshold current density and the free carrier losses versus waveguide thickness for the conventional structure with aluminum content of $50 \%$ and $90 \%(\Delta \mathrm{n}=0.166$ and 0.29 , respectively). For both structures, decreasing the waveguide thickness is accompanied by an increase of free carrier loss due to a higher optical mode overlap with the p-type cladding layer. Structures with a smaller index step between the cladding and waveguide always possess higher free-carrier losses regardless of the waveguide thickness as shown in Figure 3. For the structure with $\Delta \mathrm{n}=0.29$ $\left(\mathrm{S}_{1}\right)$, the threshold current density for $1000 \times 100 \mu \mathrm{m}^{2}$ laser is $135 \mathrm{~A} / \mathrm{cm}^{2}$ (waveguide thickness of $850 \mathrm{~nm}$ ) remains constant until the waveguide thickness reaches $650 \mathrm{~nm}$. This is due to the fact that the increase in free carrier absorption is compensated by an increase of $\Gamma_{\mathrm{QWs}}$ (see Figure 2). Below a waveguide thickness of $650 \mathrm{~nm}$ the threshold begins to increase and reaches a value of 


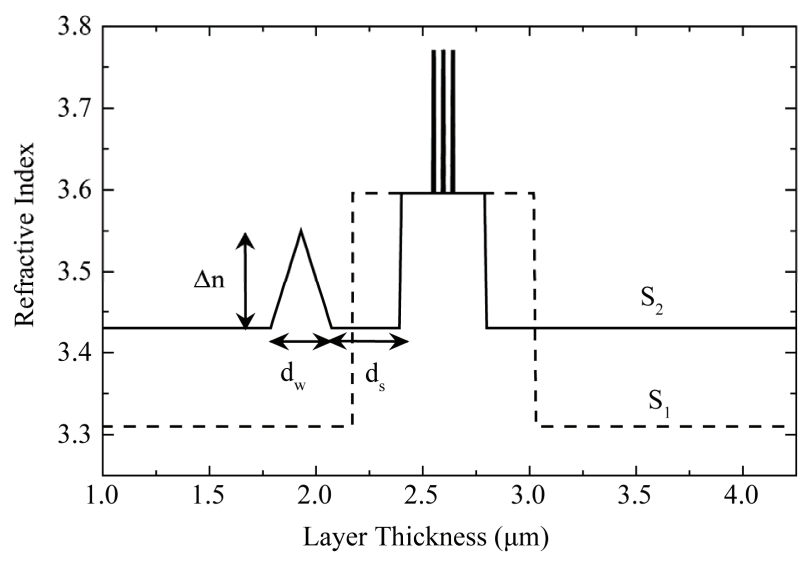

Figure 1. Refractive index profile of the conventional laser structure $S_{1}$ (dashed line) and the new laser structure $S_{2}$ (solid line).

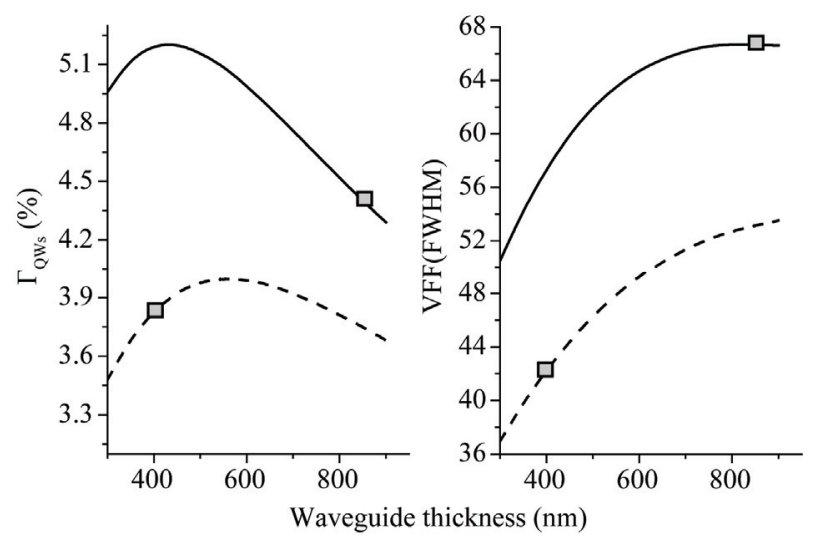

Figure 2. Quantum well confinement factor, $\Gamma_{\mathrm{QWs}}$, and vertical far-field, VFF, as a function of the waveguide thickness for a conventional rectangular waveguide for two aluminum compositions in the AlGaAsSb cladding layer (50 and $\mathbf{9 0 \%}$ indicated in the figure by dashed line and solid line, respectively).

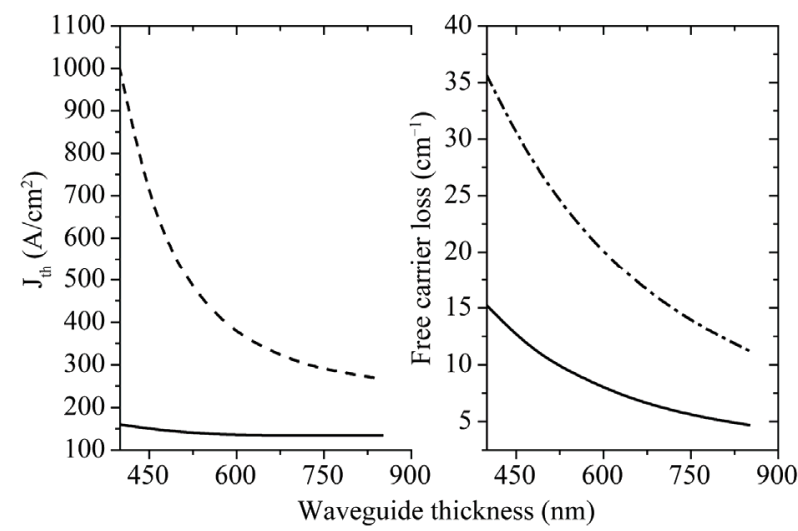

Figure 3. Threshold current density, $J_{t h}$, and free carrier loss as a function of waveguide thickness for a conventional rectangular waveguide for two aluminum content in the AlGaAsSb cladding layer $(50 \%$ and $90 \%$ indicated in the figure by dashed line and solid line, respectively).
$160 \mathrm{~A} / \mathrm{cm}^{2}$ for a waveguide thickness of $400 \mathrm{~nm}$. The situation is different in the case of the structure with $\Delta \mathrm{n}=$ 0.166 . The increase of $\Gamma_{\mathrm{QWs}}$ while decreasing the waveguide thickness is not sufficient to compensate the rapid increase of free carrier absorption as the optical field expands into cladding layers. $\mathrm{J}_{\mathrm{th}}$ increases from 245 $\mathrm{A} / \mathrm{cm}^{2}$ for a waveguide thickness of $850 \mathrm{~nm}$ to 1.01 $\mathrm{kA} / \mathrm{cm}^{2}$ for a waveguide thickness of $400 \mathrm{~nm}$ The VFF is reduced to only $42^{\circ}, \Gamma_{\mathrm{QWs}}$ is reduced to $3.83 \%, 13 \%$ lower than that for the conventional structure $\mathrm{S}_{1}$. The drawback for this design is the extremely large value of $\mathrm{J}_{\text {th }}$ which can be decreased by optimizing the doping profile in the p-type cladding layer.

In the conventional laser structure $\mathrm{S}_{1}$ the doping level in the p-type cladding layer is $5 \times 10^{18} \mathrm{~cm}^{-3}$ except the first $0.2 \mu \mathrm{m}$, which has high overlap with the optical field, where $p=5 \times 10^{17} \mathrm{~cm}^{-3}$. This doping profile provides a low internal loss of $\sim 4.7 \mathrm{~cm}^{-1}$ which increases to $35.6 \mathrm{~cm}^{-1}$ (corresponding to $\mathrm{J}_{\text {th }}=1010 \mathrm{~A} / \mathrm{cm}^{2}$ ) for the situation where the waveguide thickness is $400 \mathrm{~nm}$ and $\Delta \mathrm{n}=0.166$. Adopting the following doping profile: the first $0.5 \mu \mathrm{m}$ of the p-type cladding layer close to the waveguide is doped $\mathrm{p}=2 \times 10^{17}$ followed by $0.2 \mu \mathrm{m}$ with a linear doping ramp from $2 \times 10^{17}$ to $3 \times 10^{18} \mathrm{~cm}^{-3}$ and the remaining $p$-type cladding remains constant, $p=3 \times$ $10^{18} \mathrm{~cm}^{-3}$, leading to a decrease in the threshold current density to $\sim 190 \mathrm{~A} / \mathrm{cm}^{2}$.

Further reduction of the VFF can be accomplished by inserting a VSWW into the n-cladding layer [14]. The refractive index profile of the new structure $\left(\mathrm{S}_{2}\right)$ is shown in Figure 1. The VSWW represents a weaker waveguide compared to the waveguide core. The incorporation of the VSWW into the n-cladding layer allows an expansion of the optical near field in the vertical direction and hence decreases the corresponding VFF. In order to optimize the VFF, three parameters are modified separately: The separation, $d_{s}$, between VSWW and the waveguide core, the thickness of VSWW layer, $d_{w}$, and the aluminum content in the middle of VSWW.

Figure 4 shows the variation of $\Gamma_{\mathrm{QWs}}$ and $\mathrm{VFF}$ as a function of the separation $d_{s}$ for a VSWW thickness $d_{w}$ of $350 \mathrm{~nm}$ and for fixed aluminum content in the middle of the VSWW of $15 \%(\Delta \mathrm{n}=0.26)$. When $\mathrm{d}_{\mathrm{s}}$ is varied from $0.5 \mu \mathrm{m}$ to $1.9 \mu \mathrm{m}, \Gamma_{\mathrm{QWs}}$ increases from $3.07 \%$ to $3.76 \%$, however the VFF decreases and reaches a minimum of $35^{\circ}$ for $d_{s}=1.3 \mu \mathrm{m}$. The predicted value is lower than the lowest reported value for antimonide lasers $\left(44^{\circ}\right)$ [15]. Increasing the separation $d_{s}$ leads to an expansion of near field and subsequently a decrease in the VFF. After the separation reaches the optimum value any further increase of $d_{s}$ weakens the effect of the VSWW on the near field and hence increases again the VFF. The effect of the VSWW thickness $d_{w}$ on $\Gamma_{Q W s}$ and VFF is 


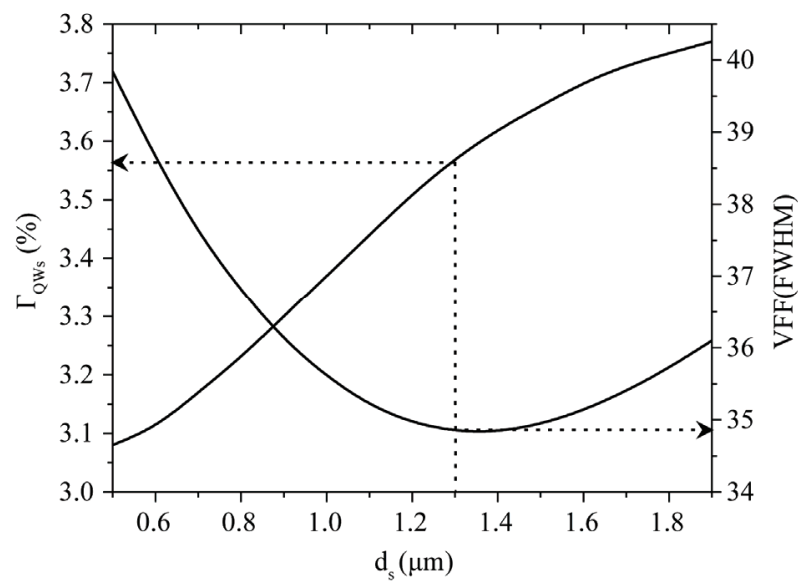

Figure 4. Quantum well confinement factor, $\Gamma_{\mathrm{QWs}}$, and vertical far-field, VFF, as a function of $d_{s}$ (separation between the $V$-shaped and rectangular waveguides) for a $350 \mathrm{~nm}$ thick $V$-shaped weaker waveguide. The aluminum content in the centre of the $\mathrm{V}$-shaped weaker waveguide is fixed to $15 \%(\Delta \mathrm{n}=0.26)$.

depicted in Figure 5 for a fixed separation $\mathrm{d}_{\mathrm{s}}=1.3 \mu \mathrm{m}$ and $15 \%$ aluminum content in the centre of the VSWW. Increasing $d_{w}$ from 0 to $500 \mathrm{~nm}$ is accompanied by a decrease of the VFF from $42^{\circ}$ to $30^{\circ}$. For $\mathrm{d}_{\mathrm{w}}=350 \mathrm{~nm}$, $\Gamma_{\mathrm{QWs}}$ decreases only by a factor of $7 \%$.

The corresponding VFF is as low as $35^{\circ}$ which represents $\sim 50 \%$ reduction from that of the conventional structure $S_{1}$ (Figure 6). A further increase of $d_{w}$, strengthen VSWW waveguide effect and will result in a broader near field and dramatic decrease in $\Gamma_{\mathrm{QWs}}$ which will lead to an increase of $\mathrm{J}_{\mathrm{th}}$. For $500 \mathrm{~nm} \mathrm{~d} \mathrm{w}_{\mathrm{w}}, \Gamma_{\mathrm{QWs}}$ reaches a minimum value of $2.84 \%, 26 \%$ lower than that obtained without a VSWW. The insertion of the VSWW allows a reduction of the VFF without affecting the threshold current; in fact our simulation shows that the threshold current density remains the same, $190 \mathrm{~A} / \mathrm{cm}^{2}$. This is expected because the slight decrease of $\Gamma_{\mathrm{OWs}}$ is compensated by a decrease in the free carrier absorption losses since the optical mode expands toward the n-type cladding layer which leads to a decrease of the optical overlap with the p-type cladding layer.

When we studied the effect of the aluminum content in the center of VSWW, similar behavior was observed. For fixed $d_{w}$ and $d_{s}$, decreasing the aluminum content in the centre of VSWW from $50 \%$ to $10 \%$ results in reduction of VFF and slight decrease in $\Gamma_{\mathrm{QWs}}$. However, low value of the Al-content will result in a stronger VSWW waveguide and therefore a dramatic decrease in $\Gamma_{\mathrm{QWs}}$.

Another alternative design to reduce VFF and maintaining low threshold current density is the use of a depressed cladding structure design. Starting from the structure with narrow optical waveguide $(400 \mathrm{~nm})$ and with a low refractive index step between the cladding

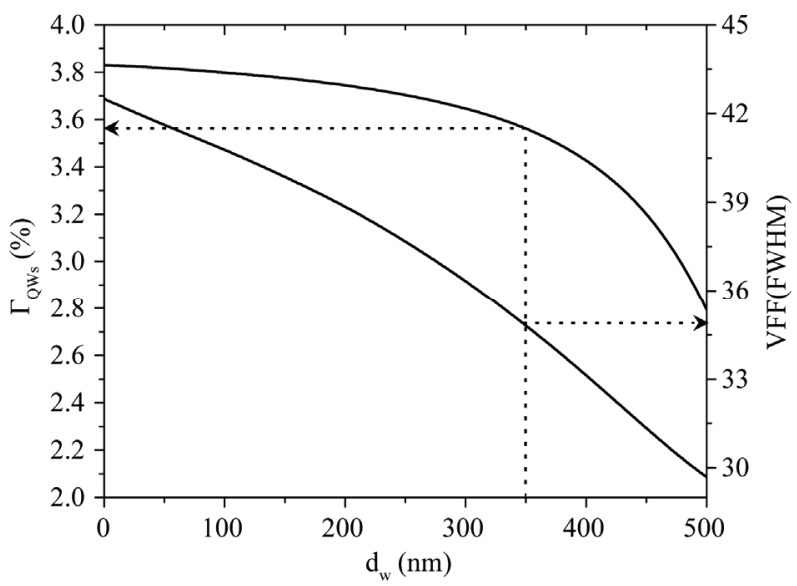

Figure 5. Quantum well confinement factor, $\Gamma_{\mathrm{QWs}}$, and vertical far-field, VFF, as a function of the thickness, $d_{w}$, of $V$-Shaped weaker waveguide. The aluminum content in the centre of the $V$-shaped weaker waveguide and $d_{s}$ are fixed to $15 \%(\Delta \mathrm{n}=0.26)$ and $1.3 \mu \mathrm{m}$, respectively.

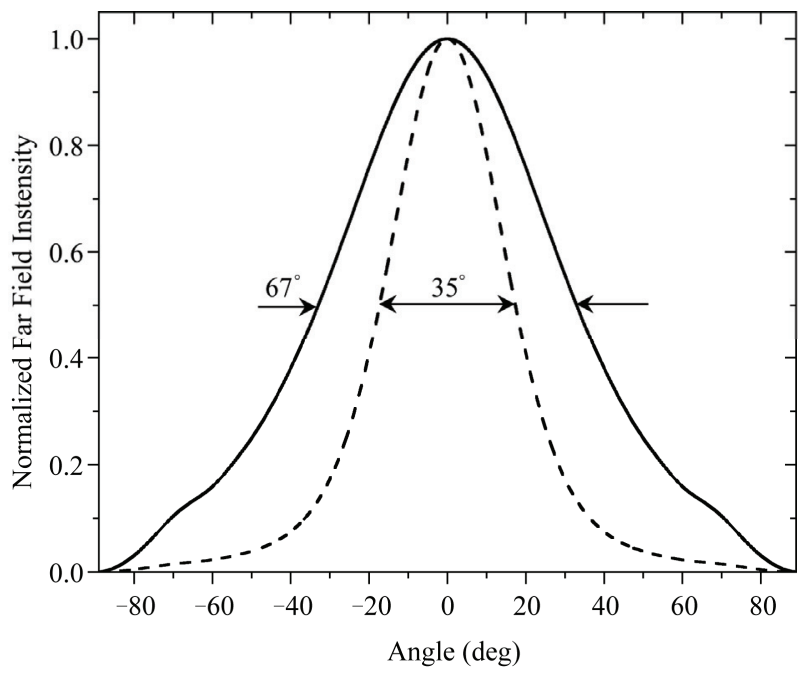

Figure 6. Vertical far-field for the conventional (solid line) and new laser design (dashed line).

and the optical waveguide $(\Delta \mathrm{n}=0.166)$ corresponding to Al content of $25 \%$ and $50 \%$ in the waveguide and cladding layers, respectively. Two thin layers with $\mathrm{Al}$ content higher than $50 \%$ are inserted between the waveguide and the claddings. These two thin layers have lower refractive index than the cladding layers and their thicknesses $\left(d_{d}\right)$ will alter the distribution of the near field and consequently VFF. The refractive index of the new Structure $\mathrm{S}_{3}$ and the previous structure with VSWW $\left(\mathrm{S}_{2}\right)$ are shown in Figure 7.

The threshold current density and VFF as a function of $d_{d}$ is shown in Figure 8. The VFF decreases from $42^{\circ}$ to $34^{\circ}$ when the thin layers thickness, $d_{d}$, increases from zero to $300 \mathrm{~nm}$ which is comparable to the value obtained by the structure with VSWW. The Al content of 


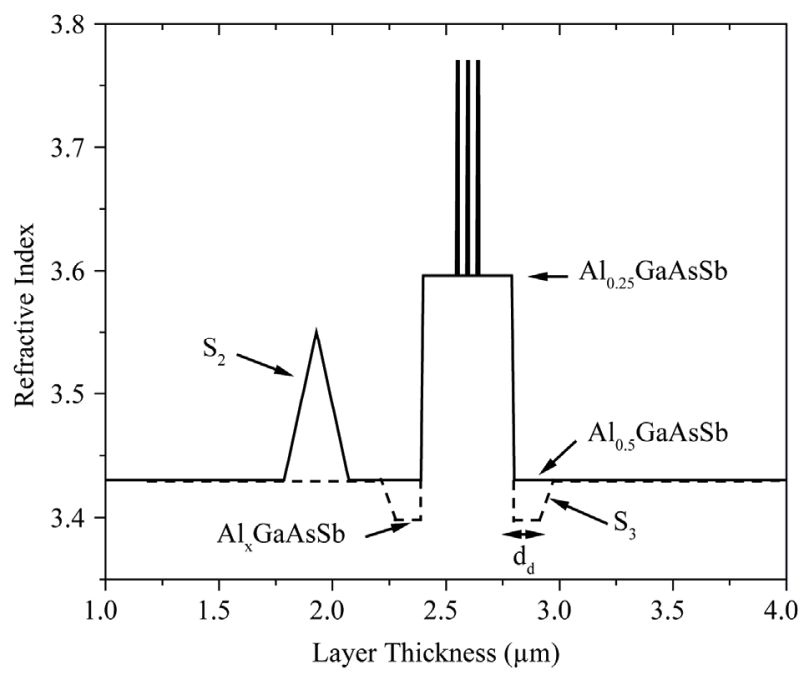

Figure 7. Refractive index profile of the structure $S_{2}$ with VSWW (solid line) and the depressed cladding structure $S_{3}$ (dashed line).

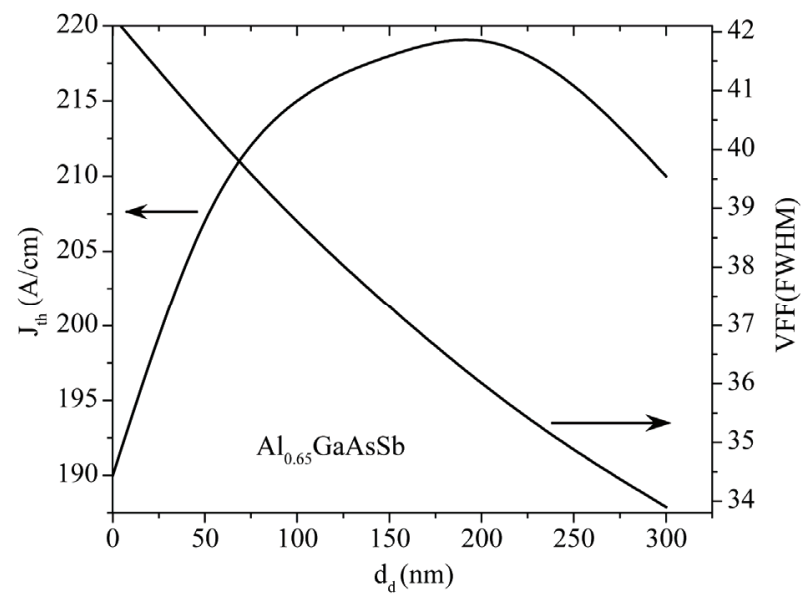

Figure 8. Threshold current density, $J_{\text {th }}$, and vertical Farfield of the depressed cladding structure $S_{3}$.

these layers is fixed to $65 \%$ in this case. As the thicknesses of these layers are increased, the optical mode is depressed and the near field becomes broader resulting in a reduction of the VFF. When increasing $d_{d}$, the threshold current density increases from $190 \mathrm{~A} / \mathrm{cm}^{2}$ and reaches a maximum of $219 \mathrm{~A} / \mathrm{cm}^{2}$ for $\mathrm{d}_{\mathrm{d}}=200 \mathrm{~nm}$, then it starts to decrease again. This behavior is linked directly to the quantum wells optical confinement factor which is not reported here. The quantum well optical confinement factor starts to decrease from $3.83 \%$ until it reaches a minimum of $3.69 \%$ then increases again to $3.72 \%$ for $d_{d}=300 \mathrm{~nm}$ which gives a threshold current density of $210 \mathrm{~A} / \mathrm{cm}^{2}$. This value is comparable to the value obtained with the structure having a VSWW in the $\mathrm{n}$-cladding layer. A further increase of the thin layers will reduce VFF, however we have to limit the thickness $d_{d}$ to $300 \mathrm{~nm}$ in order to reduce the effect of this layer on thermal conductivity with the increase of the $\mathrm{Al}$ content in these layers compared to the structure with VSWW.

\section{Conclusions}

We have reported the design of long-wavelength GaSbbased quantum well lasers with a small beam divergence while maintaining a low threshold current density. A narrow vertical far-field as low as $35^{\circ}$ can be achieved using two approaches. First design has a combination of a thin optical waveguide, reduced refractive index step between the confining and cladding layers, and a $\mathrm{V}$-Shaped weaker waveguide in the n-cladding layer. The threshold current density remains at a low value of $190 \mathrm{~A} / \mathrm{cm}^{2}$ by tapering the doping profile in the p-type cladding layer. Second design uses depressed cladding structure by inserting two thin layers with lower refractive index between the waveguide and the cladding layers resulting in low VFF and comparable threshold current density. These two designs significantly increase the light-coupling efficiency into an optical system and also have the advantage of having lower aluminum content in the structure $(50 \%$ instead of $90 \%$ in the $\mathrm{AlGaAsSb}$ cladding layers).

\section{References}

[1] M. Mattiello, M. Niklès, S. Schilt, L. Thévenaz, A. Salhi, D. Barat, A. Vicet, Y. Rouillard, R. Werner and J. Koeth, "Novel Helmholtz-based Photoacoustic Sensor for Trace Gas Detection at Ppm Level Using GaInAsSb/GaAlAsSb DFB Lasers," Spectrochimica Acta A, Vol. 63, No. 5, 2006, pp. 952-958. doi:10.1016/j.saa.2005.11.006

[2] S. Kassi, M. Chenevier, L. Gianfrani, A. Salhi, Y. Rouillard, A. Ouvrard and D. Romanini, "Looking into the Volcano with a Mid IR DFB Diode Laser and Cavity Enhanced Absorption Spectroscopy," Optics Express, Vol. 14, No. 23, 2006, pp. 11442-11452. doi:10.1364/OE.14.011442

[3] A. Salhi, Y. Rouillard. J. Angellier and M. Garcia, "Very-Low-Threshold 2.4- $\mu$ m GaInAsSb-AlGaAsSb Laser Diodes Operating at Room Temperature in the Continuous-Wave Regime," IEEE Photonics Technology Letters, Vol. 16, No. 5, 2004, pp. 2424-2426. doi:10.1109/LPT.2004.835623

[4] M. Rattunde, C. Mermelstein, J. Schmitz, R. Kiefer, W. Pletschen, M. Walther and J. Wagner, "Comprehensive Modeling of the Electro-Optical-Thermal Behavior of (Algain)(Assb)-Based $2.0 \mu \mathrm{m}$ Diode Lasers," Applied Physics Letters, Vol. 80, No. 22, 2002, pp. 4085-4087. doi:10.1063/1.1481979

[5] C. Lin, M. Grau, O. Dier and M. -C. Amann, "Low Threshold Room-Temperature Continuous-Wave Operation of 2.24 - $3.04 \mu \mathrm{m}$ GaInAsSb/AlGaAsSb Quantumwell Lasers," Applied Physics Letters, Vol. 84, No. 25, 
2004, pp. 5088-5090. doi:10.1063/1.1760218

[6] D. Z. Garbuzov, R. U. Martinelli, H. Lee, P. K. York, R. J. Menna, J. C. Connolly and S. Y. Narayan, "Ultralowloss Broadened-Waveguide High-Power $2 \mu \mathrm{m}$ Al$\mathrm{GaAsSb} / \mathrm{InGaAsSb} / \mathrm{GaSb}$ Separate-Confinement Quantum Well Lasers," Applied Physics Letters, Vol. 69, No. 7, 1996, pp. 2006-2008. doi:10.1063/1.116861

[7] J. G. Kim, L. Shterengas and G. L. Belenky, "HighPower Room-Temperature Continuous Wave Operation of 2.7 and $2.8 \mu \mathrm{m} \operatorname{In}(\mathrm{Al}) \mathrm{GaAsSb} / \mathrm{GaSb}$ Diode Lasers," Applied Physics Letters, Vol. 83, No. 10, 2003, pp. 19261928. doi:10.1063/1.1605245

[8] J. Devenson, O. Cathabard, R. Tessier and A. N. Baranov, "InAs/AlSb Quantum Cascade Lasers Emitting at 2.75-2.97 $\mu \mathrm{m}$," Applied Physics Letters, Vol. 91, No. 25, 2007. doi:10.1063/1.2825284

[9] J. Devenson, O. Cathabard, R. Tessier and A. N. Baranov, "High Temperature Operation of $\lambda \sim 3.3 \mu \mathrm{m}$ Quantum Cascade Lasers," Applied Physics Letters, Vol. 91, 2007. doi:10.1063/1.2794414

[10] L. Shterengas, G. L. Belenky, T. Hosoda, G. Kipshidze and S. Suchalkin "Continuous Wave Operation of Diode Lasers at $3.36 \mu \mathrm{m}$ at $12^{\circ} \mathrm{C}$," Applied Physics Letters, Vol. 93, 2008.
[11] M. Rattunde, J. Schmitz, R. Kiefer and J. Wagner, "Comprehensive Analysis of the Internal Losses in 2.0 $\mu \mathrm{m}$ (AlGaIn)(AsSb) Quantum-Well Diode Lasers," $A p$ plied Physics Letters, Vol. 84, No. 23, 2004, pp. 47504752. doi:10.1063/1.1760216

[12] A. Salhi and A. Al-Muhanna, "Self Consistent Analysis of Quantum Well Number Effects on the Performance of $2.3 \mu \mathrm{m}$ GaSb-Based Quantum Well Laser Diodes," IEEE Journal of Selected Topics in Quantum Electronics, Vol. 15, No. 3, 2009, pp. 918-924. doi:10.1109/JSTQE.2008.2012000

[13] FIMMWAVE and HAROLD by Photon Design http://www.photond.com

[14] B. Qiu, S. S. McDougall, X. Liu, G. Bacchin and J. H. Marsh, "Design and Fabrication of Low Beam Divergence and High Kink Free Power Lasers," IEEE Journal of Quantum Electronics, Vol. 41, No. 9, 2005, pp. 11241130. doi:10.1109/JQE.2005.853359

[15] M. T. Kelemen, J. Weber, M. Rattunde, G. Kaufel, J. Schmitz, R. Moritz, M. Mikulla and J. Wagner, "High Power $1.9 \mu \mathrm{m}$ Diode Laser Arrays with Reduced Far-Field Angle," IEEE Photonics Technology Letters, Vol. 18, No. 4, 2006, pp. 628-630. doi:10.1109/LPT.2006.870146 